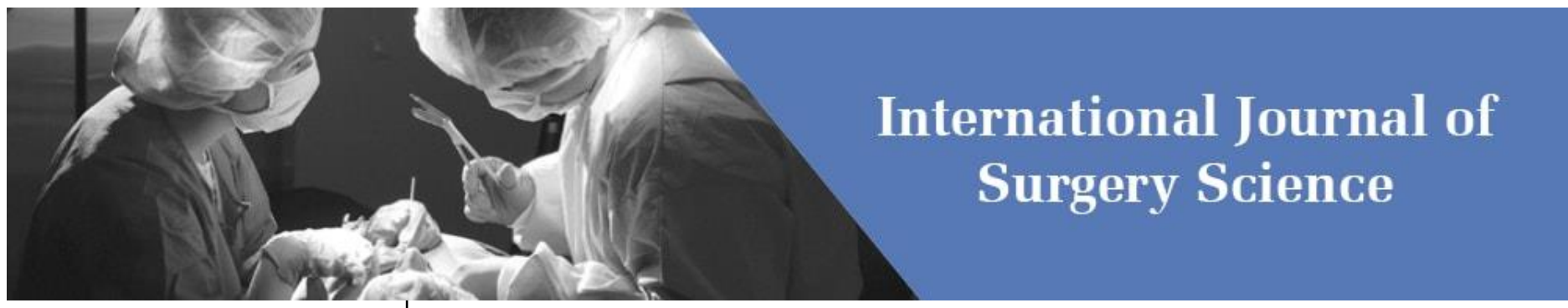

E-ISSN: 2616-3470

P-ISSN: 2616-3462

(C) Surgery Science www.surgeryscience.com

2022; 6(1): 97-100

Received: 25-11-2021

Accepted: 27-12-202

Dr. A Vijay Anand

MS, Assistant Professor,

Department of Surgery,

Trichy SRM Medical College

Hospital \& Research Centre,

Trichy, Tamil Nadu, India
Corresponding Author: Dr. A Vijay Anand

MS, Assistant Professor, Department of Surgery, Trichy SRM Medical College Hospital \& Research Centre, Trichy, Tamil Nadu, India

\section{An analytical study of acute surgical emergencies in groin hernia}

\section{Dr. A Vijay Anand}

DOI: https://doi.org/10.33545/surgery.2022.v6.i1b.829

Abstract

Aim and Objectives: This is a analytical study about various presentations, etiopathogenesis, complications and management in acute surgical emergencies in groin hernia presented in Trichy SRM medical college Hospital from May 2019 to October 2021.

Observation and Conclusions: Incidence of highest in age group of $60 \mathrm{yrs}$ to $70 \mathrm{yrs}$ and Complication of inguinal hernia was more common in males than females and it was observed hernia is commoner on the right side than on the left side. The most common symptom was groin swelling with pain followed by vomiting and most common content found in the sac was small bowel followed by omentum with the most common site of obstruction. The most common procedure followed in my study was only herniorraphy. It was followed by omentectomy.

Keywords: groin hernia, emergency hernia, complications of hernia

\section{Introduction}

\section{Aims of study}

1. To study about various presentations, etiopathogenesis, complications and management in acute surgical emergencies in groin hernia.

2. To study types of hernia that present as acute emergency

\section{Materials and Methods}

This study analytical study done in Trichy SRM medical college Hospital from May 2019 to October 2021. The study group was managed only by department of surgery. Patients are of age group of 20-88 yrs. Duration ranges from 2 hrs to 10 days, 87 cases were studied. These cases were studied from time of admission till discharge and followed up in outpatient department. A detailed history was elicited and clinical examination was done. All patients were given preoperative antibiotics and the same was continued for 4 day post operatively.

Patients in our study include those with good health to those with associated medical disorders. The results of study were later analyzed and have been presented in this study.

\section{Observation and Analysis}

Eighty seven patients were studied. Mean age of the patients was 53.25 years

Table 1: Age group

\begin{tabular}{|c|c|c|}
\hline Age group & Frequency & Percentage \\
\hline $11-20$ & 3 & 3.4 \\
\hline $21-30$ & 6 & 6.9 \\
\hline $31-40$ & 11 & 12.6 \\
\hline $41-50$ & 15 & 17.2 \\
\hline $51-60$ & 18 & 20.7 \\
\hline $61-70$ & 25 & 28.7 \\
\hline 71 and above & 9 & 10.3 \\
\hline Total & 87 & 100.0 \\
\hline
\end{tabular}

In various studies done the mean age group involved in complicated groin hernia is 60 - 70 years. In my study complicated hernia is widely distributed in age groups from 30- 70 years with maximum incidence in age group of $60-70$ years. 


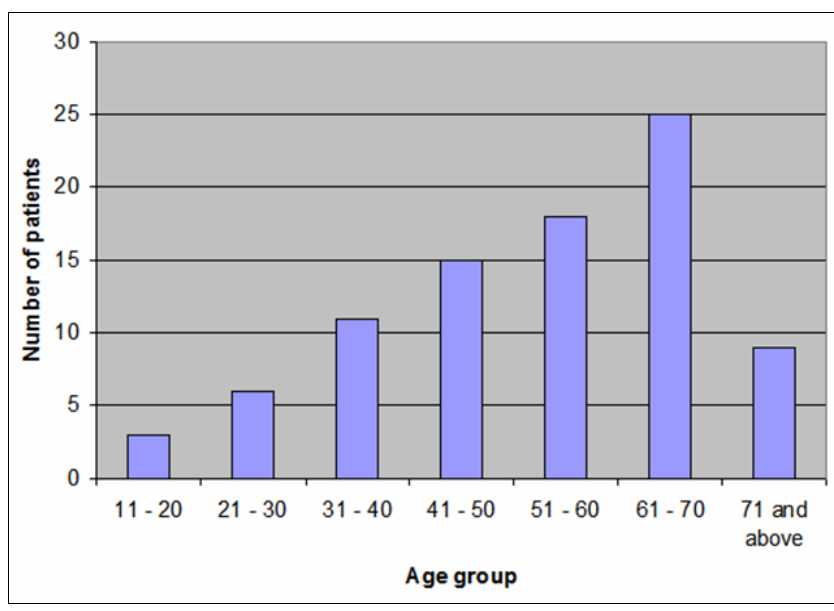

Fig 1: Age distribution

Table 2: Sex Distribution

\begin{tabular}{|c|c|c|}
\hline & Frequency & Percentage \\
\hline Female & 3 & 3.4 \\
\hline Male & 84 & 96.6 \\
\hline Total & 87 & 100.0 \\
\hline
\end{tabular}

In our study majority of the cases were males, with male to female ratio of 28:1. This shows increased incidence of complicated hernia among men.

Table 3: Types of hernia with sex

\begin{tabular}{|c|c|c|}
\hline & Inguinal & Femoral \\
\hline Female & 1 & 2 \\
\hline Male & 84 & 0 \\
\hline Total & 85 & 2 \\
\hline
\end{tabular}

In my study complicated femoral hernia was found to be more common among women, and complicated inguinal hernia was more common in men.

Table 4: Duration of hernia before acute episode

\begin{tabular}{|c|c|c|}
\hline & Frequency & Percent \\
\hline 1st year & 57 & 65.5 \\
\hline 2nd year & 16 & 18.4 \\
\hline 3rd year & 5 & 5.7 \\
\hline 4th year & 2 & 2.3 \\
\hline 5 and above years & 7 & 8.0 \\
\hline Total & 87 & 100.0 \\
\hline
\end{tabular}

\section{DURATION OF HERNIA BEFORE ACUTE EPISODE}

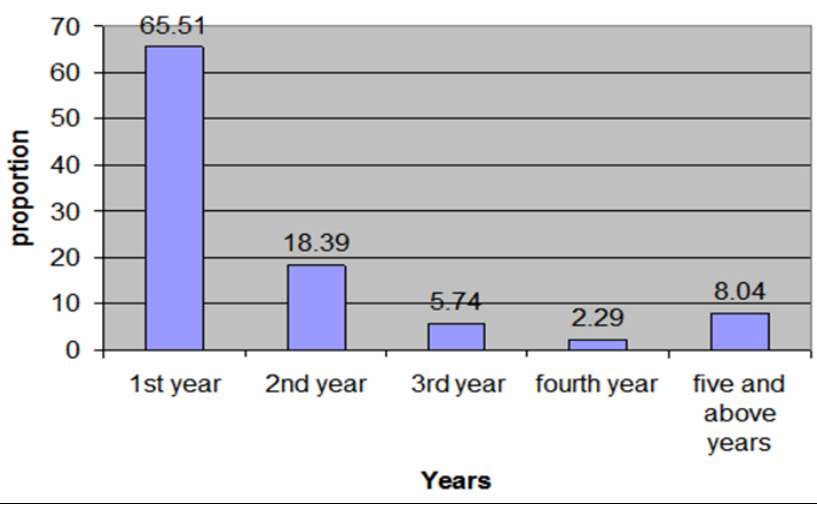

Fig 2: Duration of hernia before acute episode
Table 5: Side of hernia most commonly complicated

\begin{tabular}{|c|c|c|}
\hline & Frequency & Percentage \\
\hline Right side & 67 & 77.01 \\
\hline Left side & 20 & 22.99 \\
\hline Total & 87 & 100 \\
\hline
\end{tabular}

In my study right sided hernia was found to be more common than left sided hernia with rt: lt ratio of 3.35: 1

Table 6: Symptoms

\begin{tabular}{|c|c|c|}
\hline & Frequency & Percentage \\
\hline Pain with groin swelling & 86 & 98.9 \\
\hline Vomiting & 50 & 57.5 \\
\hline Irreducibility & 21 & 24.1 \\
\hline Abdominal distension & 16 & 18.4 \\
\hline Obstipation & 11 & 12.6 \\
\hline Nausea & 5 & 5.7 \\
\hline Fever & 2 & 2.3 \\
\hline Feculent vomiting & 1 & 1.1 \\
\hline
\end{tabular}

In my study the most common symptom was groin swelling with pain followed by vomiting.

Table 7: Contents of the hernial sac

\begin{tabular}{|c|c|c|}
\hline & Frequency & Percentage \\
\hline Small bowel & 62 & 71.3 \\
\hline Omentum & 32 & 36.8 \\
\hline Caecum & 10 & 12.5 \\
\hline Appendix & 5 & 5.7 \\
\hline Sigmoid & 4 & 4.6 \\
\hline Testis & 4 & 4.6 \\
\hline Ascending colon & 1 & 1.1 \\
\hline Transverse colon & 1 & 1.1 \\
\hline
\end{tabular}

According to Andrew et al. the most common content in the hernial sac was small intestine. In my study also the small intestine was the commonest content followed by omentum.

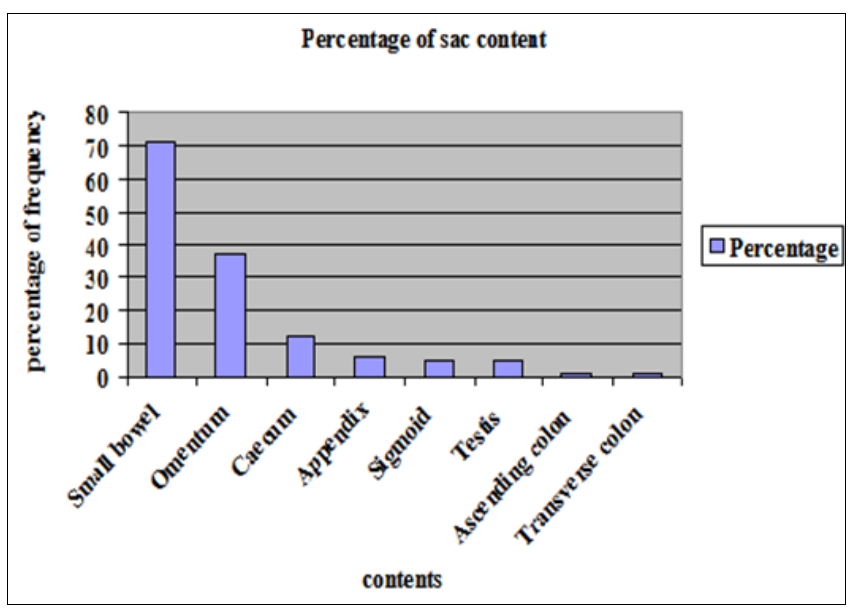

Fig 3: Percentage of sac content

Table 8: Site of obstruction

\begin{tabular}{|c|c|c|}
\hline & Frequency & Percentage \\
\hline Deep ring & 48 & 55.2 \\
\hline Superficial ring & 37 & 42.5 \\
\hline Femoral ring & 2 & 2.3 \\
\hline
\end{tabular}


In standard studies most common site of obstruction is the deep ring. In our study also the most common site of obstruction was the deep ring.

Table 9: Optimum procedure done

\begin{tabular}{|c|c|c|}
\hline & Frequency & Percentage \\
\hline Herniorrhaphy only & 46 & 52.8 \\
\hline Omentectomy & 18 & 20.7 \\
\hline Orchidectomy & 12 & 13.8 \\
\hline Resection anastomosis & 9 & 10.3 \\
\hline Kuntz & 6 & 6.9 \\
\hline Eversion of sac & 2 & 2.3 \\
\hline Appendicectomy & 1 & 1.1 \\
\hline Ileostomy & 1 & 1.1 \\
\hline \multicolumn{2}{|l}{}
\end{tabular}

In my study all patients underwent Moloney's darn repair. Darn repair was done with 1 - Prolene with three layers darn. The most common procedure done was Herniorrhaphy alone among $52.8 \%$ of the patients, followed by omentectomy in $20.7 \%$ of the patients. Resection anastomosis was done in $10.3 \%$ of the patients. Kuntz repair was done for aged and recurrent hernia patients.

Table 10: Post operative complication

\begin{tabular}{|c|c|c|}
\hline & Frequency & Percentage \\
\hline No complication & 53 & 60.9 \\
\hline Seroma & 22 & 25.3 \\
\hline Wound gaping & 7 & 8 \\
\hline Haematoma & 3 & 3.4 \\
\hline Enterocutaneous fistula & 2 & 2.3 \\
\hline
\end{tabular}

All the patients were given preoperative antibiotic, ceftriaxone $1.5 \mathrm{gm}$ IV at the beginning of the procedure and continued for four days post operatively. Most of the patients recovered without any complication (60.9\%). Most common complication was found to be seroma (25.3\%) which was managed conservatively. There were three cases of hematoma of which two needed evacuation on the third post operative day. There were seven cases of wound gaping, for which culture and sensitivity was done and appropriate antibiotics were given. All underwent secondary suturing after the infection was controlled. Two cases had enterocutaneous fistula, of which one patient died post operatively on fourth day due to systemic inflammatory response syndrome (SIRS), and the other patients were managed conservatively with spontaneous closure of the fistula.

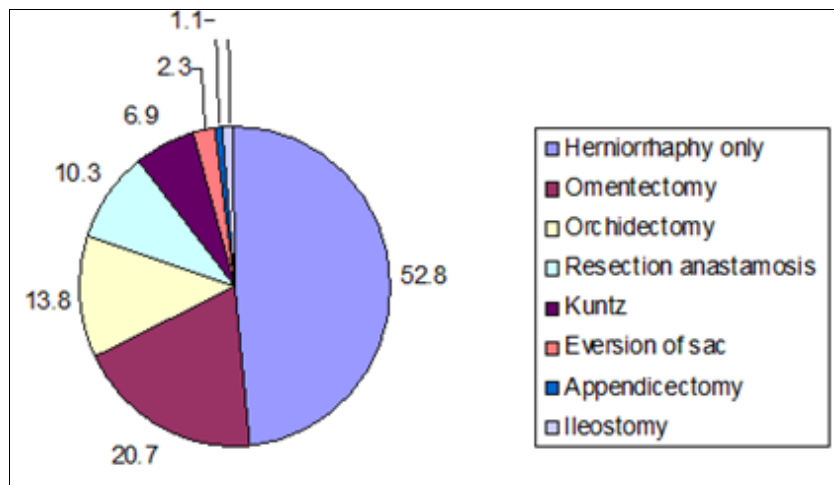

Fig 4: Percentage of different procedures done

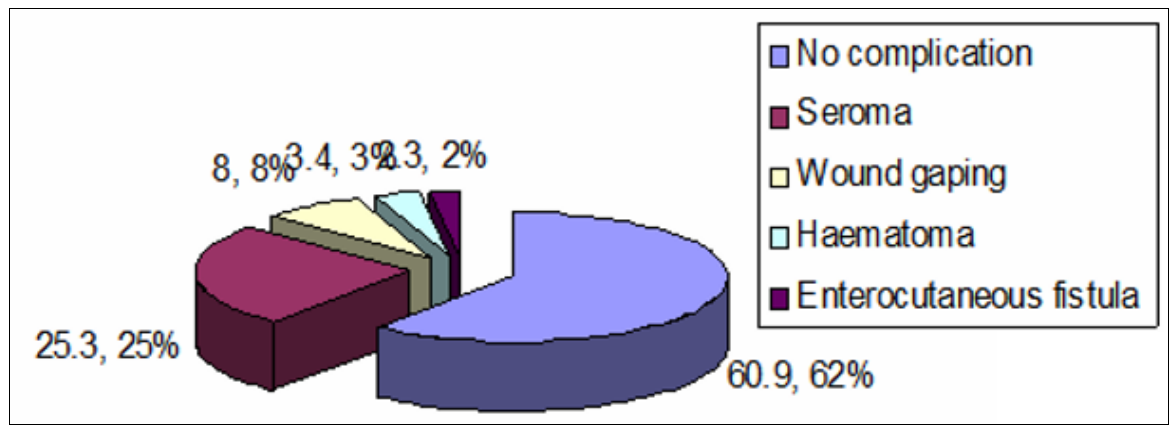

Fig 5: Proportion of post operative complication

\section{The risk of strangulation in different age group}

Series 1: Proportion of patients in that age group

Series 2: Proportion of patients with severe complications

The patients in the age group above 50 yrs were found to have strangulation. The highest numbers were seen between the age group of 61 to $70 \mathrm{yrs}$. The incidence of strangulation increased as the age increased. The percentage of patients in older age group were found to have higher incidence of strangulation with highest being in $71 \mathrm{yrs}$ and above.

\section{Conclusion}

The following observation was made in this study

1. Incidence of acute complication of groin hernia was found to be highest in age group of 60yrs to $70 \mathrm{yrs}$.

2. Complication of inguinal hernia was more common in males than females and complication of femoral hernia was more common in females than males

3. The incidence of acute complication of groin hernia is three times commoner on the right side than on the left side.
4. The average duration of hernia before acute episode was 19,45 months. Majority of acute presentation was within first year of developing hernia and more than $80 \%$ of them presented within first two years.

5. The most common symptom was groin swelling with pain followed by vomiting

6. The most common content found in the sac was small bowel followed by omentum

7. The deep ring was found to be the most common site of obstruction

8. The most common procedure followed in my study was only herniorraphy. It was followed by omentectomy.

9. Majority of the patients post operative period was uneventful. The most common complication encountered was seroma.

10. The patients with older age group were found to have strangulation more commonly than younger age group. The percentage of strangulation progressively increased from 50 years and above. 


\section{Reference}

1. Patino JF. National University of Colombia: Department of Surgery, Santa Fe Foundation of Bogota, Bogota, Colombia.

2. Lyons AS, Petrucelli RJ. Medicine; an Illustrated History. New York; Harry N Abrams publishers, 1987.

3. Rutkow IM. A Selective History of Hernia Surgery in Late Eighteenth Century: The treatises of Percivall Pott, Jean Louis Petit, D august Gottieb Richter, Don Antonio de Gimbernat and Pieter Camper. Surg Clin N Am. 2003;83:1021-1044.

4. Stoppa RE. The Midline Preperitoneal Approach and Prosthetic Repair of Groin Hernia, in Fitzgibbon.Jr. R.J, Greenburg. A.G (eds): Nyhus and Codon's Hernia, $5^{\text {th }}$ ed, Philadelphia: Lippincott Williams and Wilkins, 2002, 199.

5. Ger R. The management of certain abdominal hernia by intraabdominal closure of the neck of sac. Preliminary communication. Ann. R. Sug engl. 1982;64:342-344.

6. Arregui ME. Laparoscopic Preperitoneal Herniorraphy, Paper presented at annual meeting of the society of American Endoscopic Surgeons, Monterey, C.A, 1991.

7. Phillips EH, Carroll BJ, Fallas MJ. Laparoscopic Preperitoneal Inguinal Hernia repair without Preperitoneal incision; Surg Endosc. 1993;17:159.

8. Fitzgibbons RJ Jr, Camps T, Cornet DA, et al. Laparoscopic Inguinal Herniorraphy. Results of a multicentric trial, Ann Surg. 1995:221:3.

9. Kugel RD. The Kugel repair for Groin Hernias. Surg Clin North Am. 2003:83:1119.

10. Skandalakis JE, Sandalakis LJ, Colborn GL, Androvlakis J, Mcclusky DA, Sandalakis PN, et al. Surgical Anatomy of the Hernial rings, in Fisher. J.E. Mastery of surgery, $5^{\text {th }}$ ed Philadelphia, Lippincott Williams and Wilkins. 2007; 168:1859-1887.

11. Quinn TH. Anatomy of the Groin: A view from the Anatomist, in Fitzgibbons. R.J. Jr, Greenburg. A.G. (eds), Nyhus and Codon's Hernia, $5^{\text {th }}$ ed Philadelphia, Lippincott Williams and Wilkins. 2002, 55-70.

12. Fitzgibbons RJ Jr, Filipi CJ, Quinn TH. Inguinal Hernia in Brunicardi FC, et al. Schwartz's Principles of Surgery, $8^{\text {th }}$ ed. New York. Mc Graw Hill. 2005, 1353-1394. 